\title{
Study of genetic variants in chromosome $5 p 15.33$ region in non-smoker lung cancer patients
}

\begin{abstract}
Introduction: Genome-wide association studies have identified that genetic polymorphisms in the telomerase reverse transcriptase (TERT) and cleft lip and palate transmembrane 1-like (CLPTM1L) genes may play important roles in the development of lung cancer in never smokers.

Material and methods: This study was aiming to evaluate the associations between the risk of lung cancer in never smokers and single nucleotide polymorphisms in these genes by Real-Time Taqman assay, in forty lung cancer patients and forty apparently healthy age-matched controls selected from the chest department, Kasr Al-Ainy hospital from June 2018 to January 2019. Results: Adenocarcinoma was the most common histopathological subtype of lung cancer in the study patients. Also, the prevalence of females having adenocarcinoma was more common than males. The heterozygous form of the CLPTM1L occurred more frequently in the subjects aged above 46 years $(P=0.019)$. There was a significant association between ( $r$ 2730100) (c. 1574-3777C >A) TERT and CLPTM1L (rs 451360) (c.1532+ 1051C >A) genotypes and the incidence of lung cancer in never smokers, especially adenocarcinoma, a subtype of non-small cell lung carcinoma (NSCLC).

Conclusions: Polymorphism in the telomerase reverse transcriptase (TERT) and cleft lip and palate transmembrane 1 like (CLPTM1L) genes may play an important role in the development of NSCLC, especially adenocarcinoma subtype. The two genes are located in the chromosome 5p15.33.
\end{abstract}

Key words: genetic variation, 5 p15.33 chromosome, lung cancer, non-smokers

Adv Respir Med. 2020; 88: 485-494

\section{Introduction}

From data estimated in 2008, there were 16,632 newly diagnosed lung cancer cases among Arab league countries nationals. The majority of cases were reported in Arab countries in North Africa such as Egypt (20.6\%), followed by Morocco $(20.1 \%)$, Algeria (15.4\%) and Tunisia (10\%). Furthermore, there were a total of 15,421 deaths related to lung cancer in the Arab populations [1]. Cancer develops after genetic damage to DNA and epigenetic changes. Those changes affect the cell's normal functions, including cell proliferation, programmed cell death and DNA repair. As more damage accumulates, the risk of cancer increases [2]. Studies have demonstrated differences in epidemiological characteristics and histopathological subtypes between smokers and never smokers, which led to the suggestion of existence of non-tobacco-related risk factors in the pathogenesis of NSCLC. Possible risk factors included exposure to cooking fumes, hormones and viral infection. Additional evidence that suggested differences in tumor biology between never smokers and smokers lay in the mutational frequencies and spectra observed in the tumor tissue itself [3].

Genome-wide association studies (GWAS) have shown that the polymorphism in the telomerase reverse transcriptase (TERT) and cleft lip and palate transmembrane 1 like (CLPTM1L) genes may play important roles in the development of lung cancer. These two genes are located in chromosome 5p15.33 [4]. Telomerase expres- 
sion plays a role in cellular senescence as it is normally repressed in postnatal somatic cells resulting in shortening of telomeres. Deregulation of telomerase expression in somatic cells may be involved in oncogenesis [5]. CLPTM1L is a commonly overexpressed anti-apoptotic factor in lung tumors. Knockdown of CLPTM1L transcript in NSCLC cells results in the increase in sensitivity to genotoxic stress-mediated apoptotic killing and diminishes expression of Bcl-xL in a manner dependent on a dose of CLPTM1L expression [6].

This study investigated the association between telomerase reverse transcriptase rs 2736100 (c.1574$3777 \mathrm{C}>\mathrm{A}$ ) and cleft lip and palate transmembrane 1 like protein rs 451360 (c. $1532+1051 \mathrm{C}>\mathrm{A}$ ) single nucleotide polymorphism with lung cancer in never smokers. Moreover, it was aiming to figure out the relation between the genotypes and tumor histopathological subtypes.

\section{Material and methods}

This is a prospective study performed in the Chest Department in collaboration with the Clinical and Chemical Pathology Department, Faculty of Medicine, Cairo University during the period from June 2018 to January 2019. It was performed on 80 subjects divided into two groups; Group I included 40 lung cancer never smokers recruited from the chest department inpatients and diagnosed by bronchoscopic tissue biopsy; Group II included 40 age- and sex-matched never smokers healthy volunteers as a control group. Patients with type II respiratory failure, refractory hypoxemia, bleeding disorders, multiple organ system failure, recent angina or myocardial infarction ( $<6$ weeks) were excluded. Institutional research ethics committee has approved the study and written informed consent was obtained from all participants. Detection of telomerase reverse transcriptase and cleft lip and palate transmembrane 1 like protein was done by real-time PCR.

\section{Methodology}

Specimen collection: $3 \mathrm{~mL}$ of blood were withdrawn by aseptic venipuncture to a prechilled violet top EDTA vacutainer tubes for genomic DNA study. DNA samples were stored at $-80^{\circ} \mathrm{C}$ to be used for TaqMan real-time PCR.

Genetic analysis of telomerase reverse transcriptase rs 2736100 (c.1574-3777C >A) and cleft lip and palate transmembrane 1like protein rs 451360 (c. $1532+1051 C>A$ ) by Real-Time PCR: Analysis of TERT and CLPTM1L Polymorphisms by
Real-Time PCR using TaqMan ${ }^{\circledR}$ probes and primers on Applied biosystems ${ }^{\circledR}$ Step One Real-time PCR system: The test was done in two main steps:

\section{A. DNA extraction from peripheral blood leucocytes of EDTA anti-coagulated blood}

Principle: The kit (CinnaPure ${ }^{\circledR D N A}$ ) contains all ingredients for quick preparation of pure DNA from blood.

Equipment: Mini spin columns $50 \times$, collection tubes $(1.5 \mathrm{~mL}) 50 \times$, lysis buffer $20 \mathrm{~mL}$, precipitation buffer $15 \mathrm{~mL}$, wash buffer I $20 \mathrm{~mL}$, wash buffer II $40 \mathrm{~mL}$ and elution buffer $2 \times 1250 \mu \mathrm{L}$.

Protocol: Approximate time for total nucleic acid preparation from blood $=15 \mathrm{~min}$. Lysis buffer ( $400 \mu \mathrm{L}$ ) was added to $100 \mu \mathrm{L}$ of the sample in a sterile $1.5 \mathrm{~mL}$ polypropylene tube. Precipitation solution $(300 \mu \mathrm{L})$ was then added and vortexed at maximum speed for 5 seconds. The solution was then pipetted to a spin column with a collection tube. The tube was centrifuged at 12,100 $\times \mathrm{g}$ for $1 \mathrm{~min}$., after which the collection tube was discarded and replaced by a new one. Wash buffer I $(400 \mu \mathrm{L})$ was added to the spin column, centrifuged at $12,100 \times$ $\mathrm{g}$ for $1 \mathrm{~min}$. and flow-through discarded. The spin column was washed with $400 \mu \mathrm{L}$ wash buffer II, centrifuged for $1 \mathrm{~min}$ at 12,100 $\times \mathrm{g}$ and flow-through discarded. This step was repeated twice. The column was carefully transferred to a new $1.5 \mathrm{~mL}$ tube. Preheated elution buffer $\left(30 \mu \mathrm{L}\right.$ at $\left.65^{\circ} \mathrm{C}\right)$ was added to the center of the column which was then covered and incubated at $65^{\circ} \mathrm{C}$ for $3-5 \mathrm{~min}$. It was then centrifuged for $1 \mathrm{~min}$. at $12,100 \times \mathrm{g}$ to elute the DNA. Purified DNA was stored at $-80^{\circ} \mathrm{C}$. DNA concentration was measured spectrophotometrically by measuring optical density when ultraviolet light is absorbed at $260 \mathrm{~nm}$ by Nano drop [7].

\section{B. Amplification and real-time PCR allelic discrimination assays}

Real-time PCR with sequence-specific primers was used to assess the telomerase reverse transcriptase and cleft lip and palate transmembrane 1like protein. Real-time PCR allelic discrimination assay were designed using TaqMan SNP Genotyping Assays (Applied Bio systems) (Figure 1).

\section{Principle. TaqMan SNP Genotyping Assay}

1. Each TaqMan Minor groove binder (MGB) probe anneals specifically to its complementary sequence between the forward and reverse primer sites.

2. When the oligonucleotide probe is intact, the proximity of the reporter dye to quencher dye results in quenching of reporter fluorescence. 


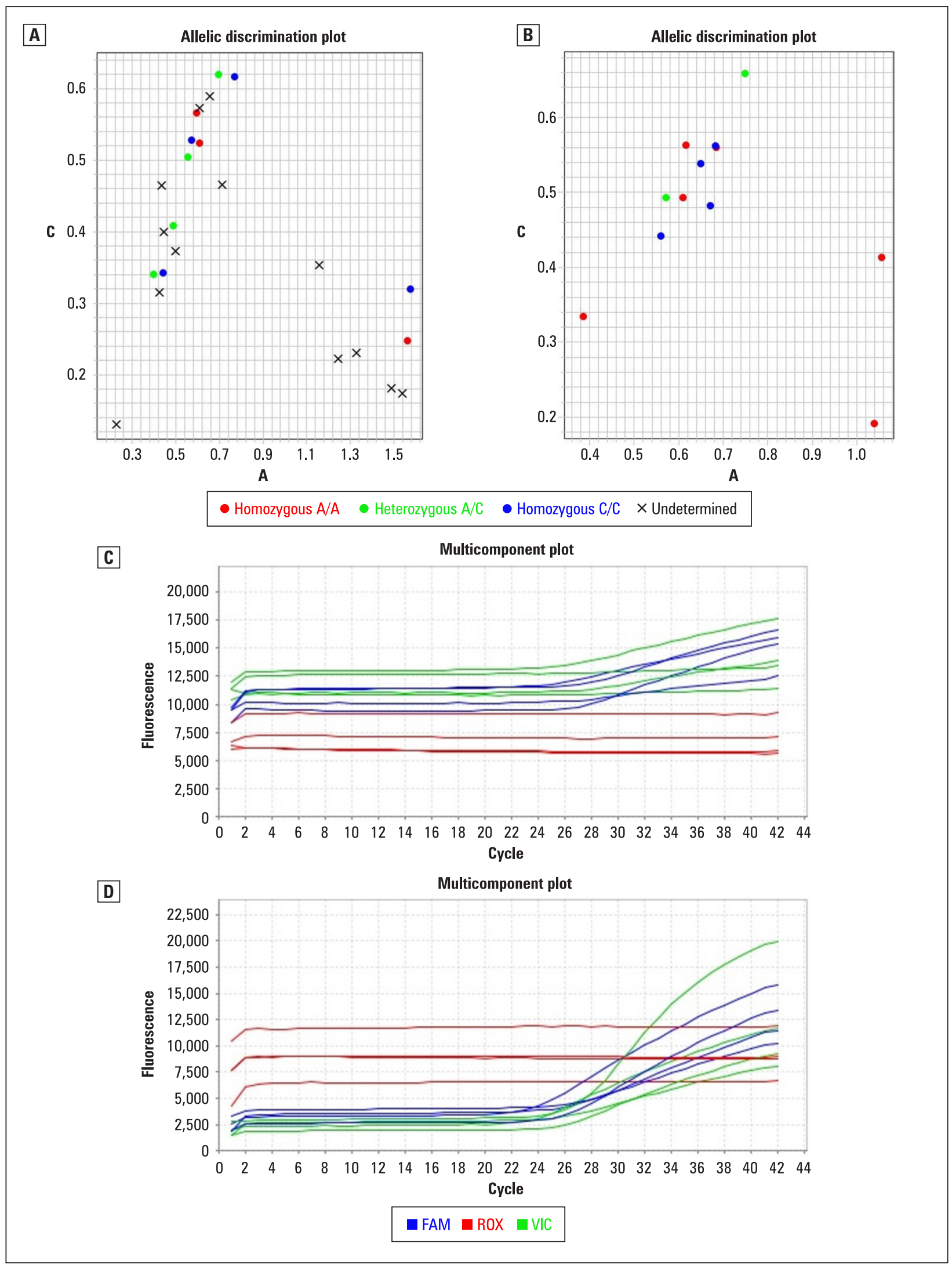

Figure 1 A. Allelic discrimination plot of TERT (rs 2736100). B. Allelic discrimination plot of CLPT1L (rs 451360). C. Multicomponent plot of TERT (rs 2736100). D. Multicomponent plot of CLPT1L (rs 451360). After PCR amplification, real-time PCR allelic discrimination assays were designed using TaqMan SNP genotyping assay (Applied Bio systems). The Sequence Detection System (SDS) Software used the fluorescence measurements made during the plate read to plot fluorescence values based on the signals from each well. Plotted fluorescence signals indicated which alleles were in each sample 
3. AmpliTaq Gold DNA polymerase extends primers bound to template DNA.

4. AmpliTaq Gold DNA polymerase cleaves only probes that are hybridized to target.

5. Cleavage separates reporter dye from quencher dye, which results in increased fluorescence by reporter.

6. Increase in fluorescence signal occurs when probes that have hybridized to complementary sequence are cleaved. Thus, fluorescence signal generated by PCR amplification indicates which alleles are present in the sample [8].

\section{Reagents}

Each of the 40× TaqMan SNP Genotyping Assay consists of a single tube containing:

1. Sequence-specific forward and reverse primers to amplify promoter region of CLPTM1L and TERT genes.

2. Two TaqMan MGB probes for distinguishing between the two alleles:

- One probe labeled with VIC dye detects Allele 1 sequence.

- One probe labeled with FAM dye detects Allele 2 sequence:

- The context sequence for TERT was Polymorphism: C > A, transition substitution.

- The context sequence for CLPTM1L was Polymorphism: C > A, transversion substitution.

Each TaqMan MGB probe contains:

1. Reporter dye at the 5' end of each probe.

- FAM dye (6-carboxyfluorescein) is linked to the 5' end of the Allele $1(\mathrm{C})$ probe.

- VIC dye is linked to the 5' end of the Allele 2 (A) probe.

2. Minor groove binder (MGB) at the 3' end of each probe. This modification increases melting temperature (Tm) for a given probe length [9], which allows the design of shorter probes.

3. Non-fluorescent quencher (NFQ) at the 3' end of each probe.

\section{Technique}

All reactions were performed in total volume of $20 \mu \mathrm{L}$ containing $10 \mu \mathrm{L}$ of master mix, $0.5 \mu \mathrm{L}$ of SNP-ready-made assay, (1-5 $\mu \mathrm{L})$ purified DNA solution according to DNA concentration which was measured to be completed to $20 \mu \mathrm{L}$ of nuclease-free water. Reaction mixture was prepared for each assay before transferring it to the optical reaction plate for thermal cycling. After adding reagents to DNA samples, they were mixed thoroughly to avoid air bubbles in the well.

\section{Allelic discrimination plate read and analysis}

After PCR amplification, an endpoint plate read was performed using an Applied Bio systems Real-Time PCR System, The Sequence Detection System (SDS) Software used the fluorescence measurements made during the plate read to plot fluorescence values based on the signals from each well. Plotted fluorescence signals indicated which alleles were in each sample. Plate read document was analyzed. Automatic allele calls were made. Allele calls were converted to genotypes (Figure 1).

\section{Statistical methods}

Data were coded and entered using the statistical package SPSS version 23. Data were summarized using mean, standard deviation, median, minimum and maximum for quantitative variables and frequencies (number of cases) and relative frequencies (percentages) for categorical variables. Comparisons between the groups were done using unpaired t test when comparing 2 groups and analysis of variance (ANOVA) with multiple comparisons post hoc test when comparing more than 2 groups. For comparing categorical data, Chi-square $(\chi 2)$ test was performed. Exact test was used instead when the expected frequency was less than 5. Genotype and allele frequencies were compared between the disease and the control groups using logistic regression. Odds ratio (OR) with 95\% confidence intervals was calculated. P-values less than 0.05 were considered statistically significant [10].

\section{Results}

Group (I) included 40 lung cancer non-smokers, their mean age was $44.13+16.18$. There were 20 females (50\%) and 20 males (50\%) in the group. Group (II) included forty healthy volunteers serving as a control group. Their mean age was $34.45+9.98$ years, and there were 31 females $(77.5 \%)$ and 9 males (22.5\%). Never smoker lung cancer patients were classified into small-cell lung carcinoma (SCLC) constituting $5 \%$ (2 patients), undifferentiated lung carcinoma constituting 5\% (2 patients) and 36 (90\%) non-smallcell lung carcinoma (NSCLC) cases, who were divided into 26 (65\%) adenocarcinoma cases, $6(15 \%)$ large-cell carcinoma and $4(10 \%)$ squamous-cell carcinoma (Figure 2).

TERT genotype distribution showed that homozygous form of the wild genotype "CC" was found in 22 (55\%) patients and 18 (45\%) 


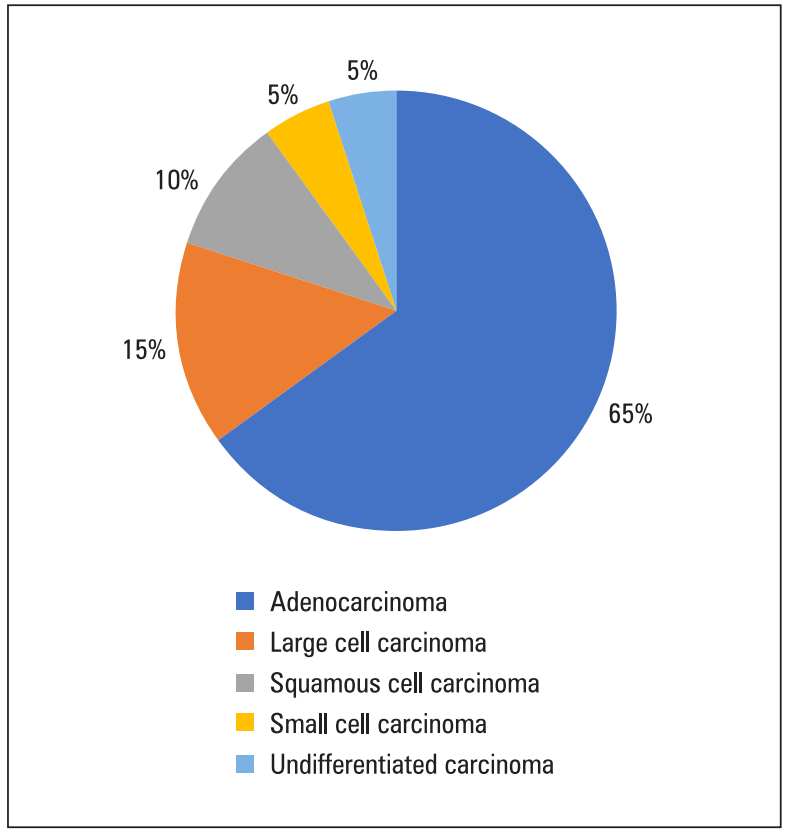

Figure 2. Classification of never smoker lung cancer patients according to the histopathological type of the tumor

individuals of the control group with no clinical significance $(\mathrm{P}=0.2)$. The heterozygous form of genotype "CA" was found in $12(30 \%)$ patients and $19(47.5 \%)$ control individuals $(\mathrm{P}=0.175)$ and the homozygous form of the mutant genotype "AA" was found in $6(16 \%)$ patients and in $3(7.5 \%)$ controls $(\mathrm{P}=0.525)$. The allelic distribution of TERT showed that "A" allele was present in $24(30 \%)$ patients and $25(31.3 \%)$ controls (P $=0.864)$, and allele "C" was found in $56(70 \%)$ patients and $55(68.8 \%)$ controls $(\mathrm{P}=0.932)$ (Figure 3A). The genotype distribution of the CLPTM1L showed that the homozygous form of the mutant genotype "AA" was found in 9 (22\%) patients in the never smoker lung cancer group, while it was found in $6(12 \%)$ individuals in the control group with no clinical significance $(\mathrm{P}=0.393)$. The heterozygous form "CA" was discovered in $31(77.5 \%)$ patients, while it was found in $34(85 \%)$ individuals of the control group ( $p=0.53$ ), and the homozygous form of the wild genotype "CC" was not detected in the two studied groups. The allelic distribution of the CLPTM1L revealed that allele "A" was found in $49(61.3 \%)$ patients and $46(57.5 \%)$ controls $(\mathrm{P}=0.629)$, and the " $\mathrm{C}$ " allele was discovered in $31(38.8 \%)$ patients and $34(42.5 \%)$ controls ( $p$ $=0.512$ ) (Figure 3B).

On combining genotypes of TERT and CLPTM1L, the homozygous form of the wild genotype "CC" of the TERT and the homozygous form of the mutant genotype "AA" of CLPTM1L was found in 1 patient and in 1 control individual constituting $2.5 \%$ of each group $(\mathrm{P}=0.884)$. On joining the homozygous form of the mutant genotypes "AA" of both SNPs (single nucleotide polymorphisms), it was found in 3 patients (7.5\%) and in 2 controls (5\%) $(\mathrm{P}=0.841)$. On combining the homozygous form of the mutant genotype "AA" of TERT with the heterozygous form "CA" of the CLPTM1L, it was found in 3 patients $(7.5 \%)$ and in $1(2.5 \%)$ of the controls $(\mathrm{P}=0.460)$. On combining the heterozygous form "CA" of TERT with the homozygous form "AA" of the mutant genotype of CLPTM1L, it was found in $5(12.5 \%)$ lung cancer patients and in $3(7.5 \%)$ controls $(\mathrm{P}=0.708)$. On combining the heterozygous form "CA" of the two SNPs, it was found in 7 (17.5\%) patients and in $16(40 \%)$ controls $(\mathrm{P}=0.06)$, and on joining the homozygous form of the wild genotype "CC" of TERT with the heterozygous form "CA" of CLPTM1L, it was found in $21(52.5 \%)$ patients and in $17(42.5 \%)$ controls $(\mathrm{P}=0.978)$.

The relations between TERT and CLPTM1L genotypes and the histopathological subtypes of lung cancer were shown in Table 1 and 2. Also, relations between the combination of genotypes of two SNPs and lung cancer histopathology were shown in Table 3 . The connection between the genotypes or the combination of genotypes of two SNPs and sex showed no statistical significance. The relation of the CLPTM1L genotypes and age uncovered that mean age of patients with heterozygous form of CLPTM1L "CA" was $46.42 \pm$ 17.28 years, while mean age of patients who had homozygous form of the mutant genotype was $36.22 \pm 8.09(\mathrm{P}=0.019)$. The relation between genotypes of TERT and age showed that mean age of patients with heterozygous form "CA" was $44.17+15.58$ years, and mean age of homozygous form of wild genotype "CC" was $46.68+17.51$, and these are older ages than the ages $(34.67+$ 9.18) of the patients showing homozygous form of mutant genotype "AA" $(\mathrm{P}=0.27)$.

\section{Discussion}

Lung cancer is one of the commonest cancer types worldwide in respect of incidence and mortality. Global statistical data showed that lung cancer alone accounts for $13 \%$ of all newly diagnosed cancers and is responsible for 18\% of all cancer deaths [11]. Lung cancer in never smokers is distinct from those in smokers in view of pathogenesis, molecular alterations, drug responsiveness and prognosis. Significant portion 
A

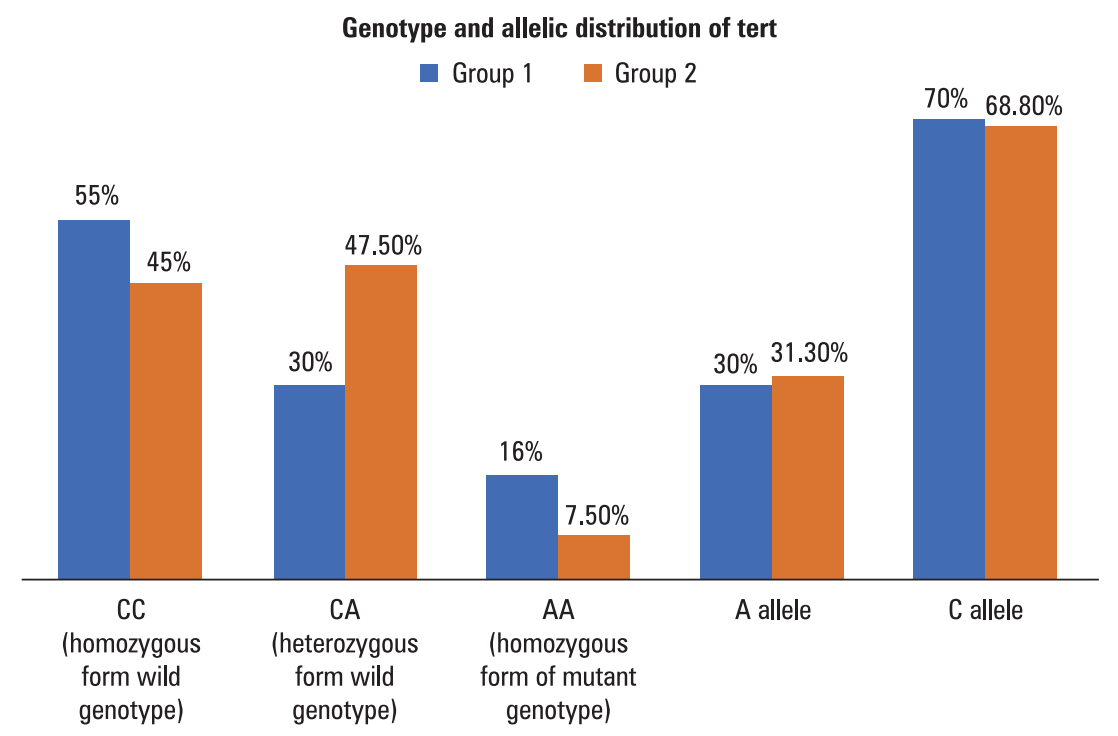

B

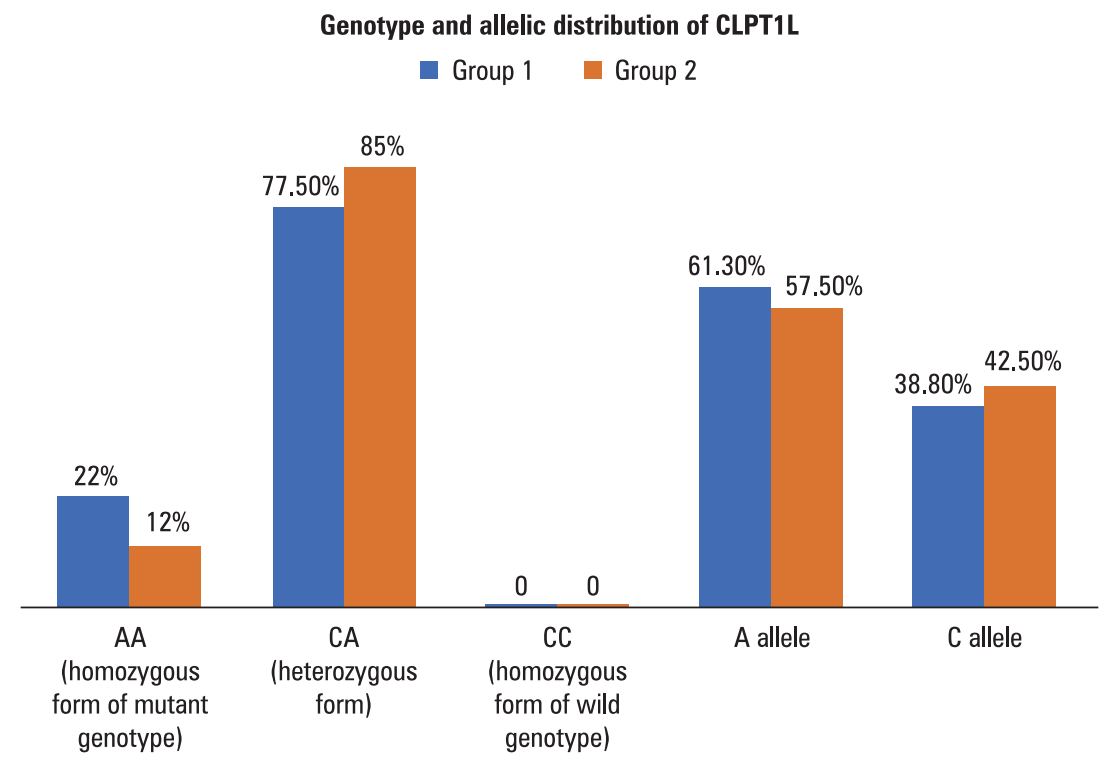

Figure 3 A. Genotype and allelic distribution of TERT (rs 2736100) (c. 1574-3777A>C). B. Genotype and allelic distribution of CLPT1L (rs 451360) (c. $1532+1051 A>C$ )

of lung cancer in never smokers harbor genetic variant in driving oncogene, to which molecular targeted drugs are dramatically sensitive. Therefore, genetic testing before the treatment is essential for lung cancer in never smokers to select the appropriate treatment option according to patient's molecular characteristics [12].

Non-smoking-associated lung cancer not only occurs in never smokers, but also in current and former smokers. Recent genome-wide association studies (GWAS) have shown that the polymorphisms in the TERT and CLPTM1L genes may play important roles in the development of lung cancer. The two genes are both located in chromosome 5p15.33 [13]. Three GWAS in European populations showed consistent associations of polymorphisms in these two genes with lung cancer in non-smokers [14].

This study analyzed the distribution of TERT and CLPTM1L single nucleotide polymorphism in patients with lung cancer in never smokers and in healthy controls in attempt to find the association between these two polymorphisms and the development of lung cancer in never 
Table 1. The relation between histopathological subtypes of lung cancer and TERT and CLPT1L genotypes among the study population

\begin{tabular}{|c|c|c|c|c|c|c|}
\hline \multirow{2}{*}{\multicolumn{2}{|c|}{ Histopathological subtype }} & \multicolumn{5}{|c|}{ TERT (rs 2736100) } \\
\hline & & \multirow{2}{*}{$\begin{array}{c}\text { AA } \\
(\mathbf{n}=\mathbf{6})\end{array}$} & \multirow{2}{*}{$\begin{array}{c}\text { CA } \\
\text { (n = 12) } \\
11(91.67 \%)\end{array}$} & \multirow{2}{*}{$\begin{array}{c}\text { CC } \\
\text { (n = 22) } \\
20(90.91 \%)\end{array}$} & \multirow{2}{*}{$\begin{array}{c}\begin{array}{c}\text { Total } \\
(\mathbf{n}=40)\end{array} \\
36(90 \%)\end{array}$} & \multirow{2}{*}{$\begin{array}{c}\text { P-value } \\
0.837\end{array}$} \\
\hline $\operatorname{NSCLC}(n=36)$ & Yes [no, \%] & & & & & \\
\hline & No $[$ no, \%] & $1(16.67 \%)$ & $1(8.33 \%)$ & $2(9.09 \%)$ & $4(10 \%)$ & \\
\hline \multirow[t]{2}{*}{$\operatorname{SCLC}(n=2)$} & Yes [no, \%] & 0 & 0 & $2(9.09 \%)$ & $2(5 \%)$ & \\
\hline & No $[$ no, \%] & $6(100 \%)$ & $12(100 \%)$ & $20(90.91 \%)$ & $38(95 \%)$ & 0.422 \\
\hline \multirow{2}{*}{$\begin{array}{l}\text { Undifferentiated } \\
\text { carcinoma }(n=2)\end{array}$} & Yes [no, \%] & $1(16.67 \%)$ & $1(8.33 \%)$ & 0 & $2(5 \%)$ & 0.206 \\
\hline & No $[$ no, \%] & $5(83.33 \%)$ & $11(91.67 \%)$ & $22(100 \%)$ & $38(95 \%)$ & \\
\hline \multicolumn{2}{|l|}{ P-value } & $0.005^{*}$ & $0.0001^{*}$ & $0.0001^{*}$ & $0.0001^{*}$ & \\
\hline \multirow{2}{*}{\multicolumn{2}{|c|}{ Histopathological subtype }} & \multicolumn{5}{|c|}{ CLPT1L (rs 451360) (c. $1532+1051 \mathrm{G}>\mathrm{T}$ ) } \\
\hline & & $\begin{array}{c}\text { AA } \\
(n=9)\end{array}$ & $\begin{array}{c}\text { CA } \\
(n=31)\end{array}$ & $\begin{array}{c}\text { CC } \\
(n=0)\end{array}$ & $\begin{array}{c}\text { Total } \\
(n=40)\end{array}$ & P-value \\
\hline \multirow[t]{2}{*}{$\operatorname{NSCLC}(n=36)$} & Yes [no, \%] & $8(88.89 \%)$ & $28(90.32 \%)$ & 0 & $36(90 \%)$ & 0.899 \\
\hline & No $[$ no, \%] & $1(11.11 \%)$ & $3(9.68 \%)$ & 0 & $4(10 \%)$ & \\
\hline \multirow[t]{2}{*}{$\operatorname{SCLC}(n=2)$} & Yes [no, \%] & $0(0.0 \%)$ & $2(6.45 \%)$ & 0 & $2(5 \%)$ & 0.434 \\
\hline & No $[$ no, \%] & $9(100 \%)$ & $29(93.55 \%)$ & 0 & $38(95 \%)$ & \\
\hline \multirow{2}{*}{$\begin{array}{l}\text { Undifferentiated } \\
\text { carcinoma }(n=2)\end{array}$} & Yes [no, \%] & $1(11.11 \%)$ & $1(3.23 \%)$ & 0 & $2(5 \%)$ & 0.339 \\
\hline & No [no, \%] & 8 (88.89\%) & $30(96.77 \%)$ & 0 & 38 (95\%) & \\
\hline \multicolumn{2}{|l|}{ P-value } & $0.0007^{*}$ & $0.0001 *$ & - & $0.0001 *$ & \\
\hline
\end{tabular}

${ }^{*} \mathrm{P}$ value $<0.05$ is considered significant.

NSCLC — non-small cell lung carcinoma; TERT — telomerase reverse transcriptase; SCLC — small cell lung carcinoma

smokers. Never smokers lung cancer patients were classified according to histopathological subtype of lung cancer into small-cell lung carcinoma (5\%), undifferentiated lung carcinoma (5\%) and non-small-cell lung carcinoma (90\%). Then NSCLC patients were further divided into adenocarcinoma (65\%), large-cell carcinoma (15\%), squamous-cell carcinoma (10\%) (Figure 2). Adenocarcinoma was most prevalent subtype. This agreed with Sun et al. [15] who stated that smoking-related carcinogens act on both proximal and distal airways of the lung inducing all major types of lung cancer. Also, they stated that cancers arising in never smokers target distal airways and favor the adenocarcinoma type. Subramanian and Govindan [16] mentioned that adenocarcinoma is the most common type occurring in never smokers. Again, Landi et al. [17] have established that locus on chromosome 5 p15.33 is distinctly associated with a risk of lung adenocarcinoma and not with other major histological types. Also, Henschke et al. [18] found that women are commonly diagnosed when screened, and Patel et al. [19] showed that wom- en outnumber men among lung cancer patients who never smoked regularly. The study done by Samet et al. [20] showed that adenocarcinoma is more prevalent in females. This is explained by the hypothesis that females are more prone to exposure to second-hand smoke, household exposure of coal used for cooking, hormone replacement therapy, use of antiaging drugs which elongate telomeres thus escaping apoptosis and lead to cancers [21].

In the present study, there was a statistically significant difference in mean age between the patients demonstrating heterozygous form of CLPTM1L "CA" and those showing homozygous form of mutant genotype AA" $(\mathrm{P}=0.019)$. Although age difference between different genotype of TERT was statistically insignificant $(\mathrm{P}=0.27)$, the patients with heterozygous form CA and homozygous form of wild genotype "CC" were older than patients showing homozygous form of mutant genotype "AA". This agreed with Wakelee et al. [22] who mentioned that lung cancer in never smokers occurs more commonly after the age of forty. 
Table 2. The relation between histopathological subtypes of non-small cell lung cancer and TERT and CLPT1L genotypes among the study population

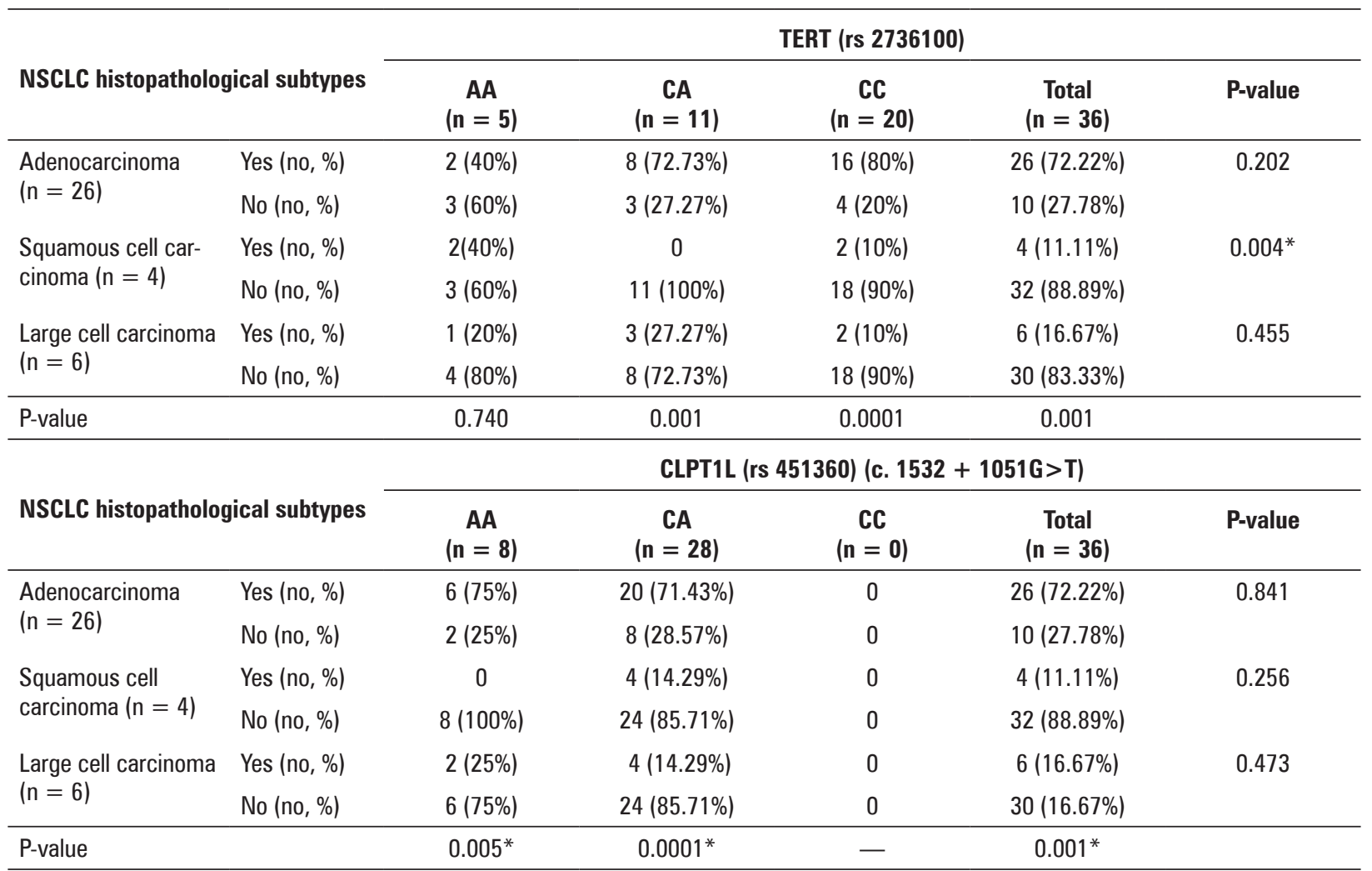

* $P$ value $<0.05$ is considered significant.

NSCLC — non-small cell lung carcinoma; TERT — telomerase reverse transcriptase; SCLC — small cell lung carcinoma

Table 3. The combination of genotypes of two SNPs and the histopathological subtypes of lung cancer

\begin{tabular}{lccccccc}
\hline Groups & $\begin{array}{c}\text { CC/AA } \\
(\mathbf{n}=\mathbf{1})\end{array}$ & $\begin{array}{c}\text { AA/AA } \\
(\mathbf{n}=3)\end{array}$ & $\begin{array}{c}\text { AA/CA } \\
(\mathbf{n}=\mathbf{3})\end{array}$ & $\begin{array}{c}\text { CA/AA } \\
(\mathbf{n}=\mathbf{5})\end{array}$ & $\begin{array}{c}\text { CA/CA } \\
(\mathbf{n}=\mathbf{7})\end{array}$ & $\begin{array}{c}\text { CC/CA } \\
(\mathbf{n}=21)\end{array}$ & P \\
\hline Adenocarcinoma & $1(100 \%)$ & $2(66.7 \%)$ & 0 & $3(60 \%)$ & $5(71.4 \%)$ & $15(71.4 \%)$ & $<0.001^{*}$ \\
Squamous cell carcinoma & 0 & 0 & $2(66.7 \%)$ & 0 & 0 & $2(9.5 \%)$ & 0.15 \\
Large cell carcinoma & 0 & $1(33.3 \%)$ & 0 & $1(20 \%)$ & $2(28.6 \%)$ & $2(9.5 \%)$ & 0.54 \\
SCLC & 0 & 0 & 0 & 0 & 0 & $2(9.5 \%)$ & 0.07 \\
Undifferentiated carcinoma & 0 & 0 & $1(33.3 \%)$ & $1(20 \%)$ & 0 & 0 & 0.54 \\
$\mathrm{P}$ & 0.4 & 0.25 & 0.25 & 0.19 & $0.008^{*}$ & $<0.001^{*}$ \\
\hline
\end{tabular}

${ }^{*} P$ value $<0.05$ is considered significant.

SCLC — small cell lung carcinoma

There was no statistically significant difference between never smoker lung cancer patients and the controls in TERT genotype distribution regarding homozygous form of wild genotype "CC", heterozygous form of genotype "CA" and homozygous form of mutant genotype "AA". Also, allelic distribution of TERT showed that the "A" allele and allele "C" didn't differ in distribution between the cases and controls. Wang et al. [23] showed that TERT SNPs is a risk factor for developing lung can- cer in never smokers. Again, case-control study by Liao et al. [24] revealed the statistical significance between AC and CC genotypes, as well as C allele of rs2736100 in TERT gene and increased risks of lung cancer in never smokers. This is explained by various ethnic populations, besides, a difference in defining investigating groups and small sample size, a dissimilarity in their genetic backgrounds, geographical differences in allelic frequencies and complexity of the disease. 
The distribution of CLPT1L genotypes and allelic distribution showed non-significant difference between never smoker lung cancer patients and healthy controls. Also, Sun et al. [25] found no association of XRCC1 and CLPTM1L polymorphisms with NSCLC in non-smoking Han Chinese population. However, Pande et al. [26] revealed additional SNPs that may be susceptibility markers for lung cancer risk in smokers (rs4975615) and never smokers (rs451360) of clinical significance. Also, the case-control study by Liang et al. [27] found that rs451360, an intronic SNP within CLPTM1L gene, was significantly associated with lung cancer risk in never smokers. Possible explanations for the same polymorphism to have different roles in cancer susceptibility can occur because that allele under investigation can be masked by the presence of other genes involved in disease development. Thus, results available regarding effect of polymorphisms on cancer risk and development should be interpreted with caution.

TERT genotypes including homozygous form of mutant genotype "AA", heterozygous form "CA" and homozygous form of wild genotype "CC" were significantly found in NSCLC patients constituting $83.33 \%, 91.67 \%$ and $90.91 \%$, respectively, of lung cancer non-smoker patients. CLPTM1L genotypes including homozygous form of mutant allele "AA" and heterozygous genotype "CA" were detected significantly in NSCLC patients constituting $88.89 \%$ and $90.32 \%$, respectively (Table 2 ). TERT and CLPTM1L genotypes were significantly presented in adenocarcinoma compared to squamous-cell carcinoma and large-cell carcinoma (Table 3). On combining homozygous form of wild genotypes "CC" of TERT and homozygous form of mutant genotype "AA", was found in adenocarcinoma (100\%). On joining homozygous form of mutant genotype "AA" in both SNPs, was found in adenocarcinoma (66.7\%) and large-cell carcinoma (33.3\%). On combining homozygous form of mutant genotype of TERT "AA" with heterozygous form of CLPTM1L "CA", was found in squamous-cell carcinoma (66.7\%) and undifferentiated carcinoma (33.3\%). On combining heterozygous form of TERT "CA" with homozygous form of mutant genotype of CLPTM1L "AA", was found in adenocarcinoma (60\%), large-cell carcinoma (20\%) and undifferentiated carcinoma (20\%). On combining heterozygous form "CA" of both SNPs, was found in adenocarcinoma 5 (71.5\%) and large-cell carcinoma (28.6\%) with statistical significance $(\mathrm{P}=0.008)$. On combining homozygous form of wild genotype of TERT "CC" with heterozygous form of CLPT1L (CA), was found in adenocarcinoma (71.4\%), squamous-cell carcinoma (9.5\%), large-cell carcinoma (9.5\%), small-cell carcinoma (9.5\%) with statistical significance (P $<0.001$ ). Also, there was statistical significance regarding the association of adenocarcinoma and some combined genotypes, mainly "CC/AA, CA/CA and CC/CA" ( $\mathrm{P} \leq 0.001)$. This agreed with Yuan et al. [28] who demonstrated that TERT rs 2736100 polymorphism is a risk factor associated with increased lung cancer susceptibility, particularly for lung adenocarcinoma. Also, Hsiung et al. [29] reported conclusive evidence that common genetic variants in TERT-CLPTM1L locus on chromosome 5p15.33 are associated with a risk for lung adenocarcinoma in non-smoking Asian women. Again, Zhao et al. [30] showed a significant association of 5p15.33 (TERT-CLPT$M 1 L$ genes) with lung cancer in the Chinese Han population.

Again, Bhat et al. [31] suggested that rs2853677 of TERT was significantly associated with multiple cancers, and it could be a potential marker for diagnosis of non-small-cell lung cancer and leukemia. Our study together with Bhat et al study highlighted the role of telomere-associated pathways in non-small-cell lung cancer. On the other hand, Hung et al. [32] suggested that $\mathrm{SNPs} /$ regions connected with lung cancer risk in never smokers are not specific for this type of cancer but rather have pleiotropic effects. Also, they found that genetic susceptibility to lung cancer in never smokers is associated with genetic variants with pan-cancer risk effects, and they mentioned that the comparison with smokers discovered that top variants previously shown to be associated with lung cancer risk only confer risk in the presence of tobacco exposure, underscoring the importance of gene-environment interactions in the etiology of this disease. Similarly, Wang et al. [33] performed a pleiotropic analysis to explore the shared susceptibility mechanisms between non-lung cancers and lung cancer and found that genetic variants identified from other cancer types were also significantly associated with the risk of lung cancer.

In conclusion, polymorphism in TERT and CLPTM1L genes may play an important role in the development of NSCLC, especially the adenocarcinoma subtype. The two genes are located in the chromosome $5 \mathrm{p} 15.33$. It is necessary to conduct large-scale population study on Egyptian patients to elucidate our results. It is recommended to do further studies using more advanced molecular techniques as complete sequence analysis for 
proper evaluation and assessment of the TERT and CLPT1L single nucleotide polymorphism as a predictive marker of lung cancer in Egyptian non-smoker individuals for early diagnosis of lung cancer.

\section{Conflict of interest}

None declared.

\section{References:}

4. Ferlay J, Shin HR, Bray F, et al. Estimates of worldwide burden of cancer in 2008: GLOBOCAN 2008. Int J Cancer. 2010; 127(12): 2893-2917, doi: 10.1002/ijc.25516, indexed in Pubmed: 21351269.

5. Jackson M, Marks L, May GHW, et al. The genetic basis of disease. Essays Biochem. 2018; 62(5): 643-723, doi: 10.1042/ EBC20170053, indexed in Pubmed: 30509934.

6. Gealy R, Zhang L, Siegfried JM, et al. Comparison of mutations in the p53 and K-ras genes in lung carcinomas from smoking and nonsmoking women. Cancer Epidemiol Biomarkers Prev. 1999; 8 (4 Pt 1): 297-302. Erratum in: Cancer Epidemiol Biomarkers Prev. 2001; 10(12): 1309.

7. Kachuri L, Amos CI, McKay JD, et al. EPIC Study. Lung cancer susceptibility locus at 5p15.33. Nat Genet. 2008; 40(12): 14041406, doi: 10.1038/ng.254, indexed in Pubmed: 18978790.

8. Bernal A, Tusell L. Telomeres: implications for cancer development. Int J Mol Sci. 2018; 19(1), doi: 10.3390/ijms19010294, indexed in Pubmed: 29351238.

9. Taylor JK, Zhang QQ, Monia BP, et al. Inhibition of Bcl-xL expression sensitizes normal human keratinocytes and epithelial cells to apoptotic stimuli. Oncogene. 1999; 18(31): 4495-4504, doi: 10.1038/sj.onc.1202836, indexed in Pubmed: 10442640.

10. Huss VA, Festl H, Schleifer KH. Studies on the spectrophotometric determination of DNA hybridization from renaturation rates. Syst Appl Microbiol. 1983; 4(2): 184-192, doi: $\underline{10.1016 /}$ S0723-2020(83)80048-4, indexed in Pubmed: 23194591.

11. Pfaffl M, Hageleit M. Validities of mRNA quantification using recombinant RNA and recombinant DNA external calibration curves in real-time RT-PCR. Biotechnology Letters. 2001; 23(4): 275-282.

12. Afonina I, Zivarts M, Kutyavin I, et al. Efficient priming of PCR with short oligonucleotides conjugated to a minor groove binder. Nucleic Acids Res. 1997; 25(13): 2657-2660, doi: 10.1093/ nar/25.13.2657, indexed in Pubmed: 9185578.

13. Chan YH. Biostatistics 101: data presentation. Singapore Med J. 2003; 44(6): 280-285, indexed in Pubmed: 14560857.

14. Bray F, Ferlay J, Soerjomataram I, et al. Global cancer statistics. CA Cancer J Clin. 2011; 61(2): 69-90, doi: 10.3322/caac.20107, indexed in Pubmed: 21296855.

15. Lee YJ, Kim JH, Kim SeK, et al. Lung cancer in never smokers: change of a mindset in the molecular era. Lung Cancer. 2011; 72(1): 9-15, doi: 10.1016/j.lungcan.2010.12.013, indexed in Pubmed: 21272954.

16. Kachuri L, Amos CI, McKay JD, et al. Lung cancer susceptibility locus at 5p15.33. Nat Genet. 2008; 40(12): 1404-1406, doi: 10.1038/ng.254, indexed in Pubmed: 18978790.

17. Rafnar T, Sulem P, Stacey SN, et al. Sequence variants at the TERT-CLPTM1L locus associate with many cancer types. Nat Genet. 2009; 41(2): 221-227, doi: 10.1038/ng.296, indexed in Pubmed: 19151717.

18. Sun S, Schiller JH, Gazdar AF. Lung cancer in never smokers a different disease. Nat Rev Cancer. 2007; 7(10): 778-790, doi: 10.1038/nrc2190, indexed in Pubmed: 17882278.

19. Subramanian J, Govindan R. Lung cancer in never smokers: a review. J Clin Oncol. 2007; 25(5): 561-570, doi: 10.1200/ ICO.2006.06.8015, indexed in Pubmed: 17290066.
20. Landi MT, Zhao Y, Rotunno M, et al. MicroRNA expression differentiates histology and predicts survival of lung cancer. Clin Cancer Res. 2010; 16(2): 430-441, doi: 10.1158/1078-0432. CCR-09-1736, indexed in Pubmed: 20068076.

21. Henschke CI, Yankelevitz DF, Libby DM, et al. Early lung cancer action project: annual screening using single-slice helical CT. Ann N Y Acad Sci. 2001; 952: 124-134, doi: 10.1111/ j.1749-6632.2001.tb02733.x, indexed in Pubmed: 11795431.

22. Patel JD, Bach PB, Kris MG. Lung cancer in US women: a contemporary epidemic. JAMA. 2004; 291(14): 1763-1768, doi: 10.1001/jama.291.14.1763, indexed in Pubmed: 15082704.

23. Samet JM, Avila-Tang E, Boffetta P, et al. Lung cancer in never smokers: clinical epidemiology and environmental risk factors. Clin Cancer Res. 2009; 15(18): 5626-5645, doi: 10.1158/10780432.CCR-09-0376, indexed in Pubmed: 19755391.

24. Subramanian J, Regenbogen T, Nagaraj G, et al. Review of ongoing clinical trials in non-small-cell lung cancer: a status report for 2012 from the ClinicalTrials.gov Web site. J Thorac Oncol. 2013; 8(7): 860-865, doi: 10.1097/JTO.0b013e318287c562, indexed in Pubmed: 23478543.

25. Wakelee HA, Chang ET, Gomez SL, et al. Lung cancer incidence in never smokers. J Clin Oncol. 2007; 25(5): 472-478, doi: 10.1200/JCO.2006.07.2983, indexed in Pubmed: 17290054.

26. Wang Y, Broderick P, Webb E, et al. Common 5p15.33 and 6p21.33 variants influence lung cancer risk. Nat Genet. 2008; 40(12): 1407-1409, doi: 10.1038/ng.273, indexed in Pubmed: 18978787.

27. Liao Y, Guo S, Chen Y, et al. VSIG4 expression on macrophages facilitates lung cancer development. Lab Invest. 2014; 94(7): 706-715, doi: 10.1038/labinvest.2014.73, indexed in Pubmed: 24862966 .

28. Sun Y, Zhang YJ, Kong XM. No association of XRCC1 and CLPTM1L polymorphisms with non-small cell lung cancer in a non-smoking Han Chinese population. Asian Pac J Cancer Prev. 2013; 14(9): 5171-5174, doi: 10.7314/apicp.2013.14.9.5171, indexed in Pubmed: 24175795.

29. Pande M, Spitz MR, Wu X, et al. Novel genetic variants in the chromosome 5p15.33 region associate with lung cancer risk. Carcinogenesis. 2011; 32(10): 1493-1499, doi: 10.1093/carcin/ bgr136, indexed in Pubmed: 21771723.

30. Liang Y, Thakur A, Gao L, et al. Correlation of CLPTM1L polymorphisms with lung cancer susceptibility and response to cisplatin-based chemotherapy in a Chinese Han population. Tumour Biol. 2014; 35(12): 12075-12082, doi: 10.1007/s13277014-2508-6, indexed in Pubmed: 25155038.

31. Yuan Y, Lu C, Xue L, et al. Association between TERT rs2736100 polymorphism and lung cancer susceptibility: evidence from 22 case-control studies. Tumour Biol. 2014; 35(5): 4435-4442, doi: 10.1007/s13277-013-1583-4, indexed in Pubmed: 24390616.

32. Hsiung CA, Lan Q, Hong YC, et al. The 5 p15.33 locus is associated with risk of lung adenocarcinoma in never-smoking females in Asia. PLoS Genet. 2010; 6(8), doi: 10.1371/journal. pgen.1001051, indexed in Pubmed: 20700438.

33. Zhao Z, Li C, Yang L, et al. Significant association of 5p15.33 (TERT-CLPTM1L genes) with lung cancer in Chinese Han population. Exp Lung Res. 2013; 39(2): 91-98, doi: 10.3109/01902148.2012.762436, indexed in Pubmed: 23368278.

34. Bhat GhR, Bhat A, Verma S, et al. Association of newly identified genetic variant rs2853677 of TERT with non-small cell lung cancer and leukemia in population of Jammu and Kashmir, India. BMC Cancer. 2019; 19(1): 493, doi: 10.1186/s12885019-5685-2, indexed in Pubmed: 31126249.

35. Hung RJ, Spitz MR, Houlston RS, et al. Lung cancer risk in never-smokers of european descent is associated with genetic variation in the 515.33 tert-clptm1ll region. J Thorac Oncol. 2019; 14(8): 1360-1369, doi: 10.1016/j.jtho.2019.04.008, indexed in Pubmed: 31009812 .

36. Wang L, Zhu M, Wang Y, et al. Cross-Cancer pleiotropic analysis reveals novel susceptibility loci for lung cancer. Front Oncol. 2019; 9: 1492, doi: 10.3389/fonc.2019.01492, indexed in Pubmed: 32010612. 